\title{
Electrochemistry of organic, bioactive compounds and biopolymers
}

\author{
Miroslav Fojta ${ }^{1}$ Tomáš Navrátil ${ }^{2}$
}

Received: 10 March 2015/Accepted: 13 March 2015/Published online: 11 April 2015

(C) Springer-Verlag Wien 2015

This Special Issue of Chemical Monthly is dedicated to lectures presented at two international meetings which took place in May 2014 in the Czech Republic: Modern Electrochemical Methods XXXIV (MEM, May 19-23, 2014, in Jetrichovice) and 47th Heyrovsky Discussion (HD, May 25-29, 2014, in Trest). Both events were parts of traditional conference series. The HD series was initiated in 1967 and it has been organized annually to cover specific topics of electrochemistry and electroanalytical chemistry in particular years. Trest castle in the center of BohemianMoravian Highlands has been the venue where the HD series has been held in the last years with only few exceptions (e.g., in 2012 HD took place in Brno, in 1992 in Bechyne). The first appearance of the MEM conference was in 1980 in Mezni Louka, Czech Republic. Particular events of this series were held at different places of the Czech Republic (e.g., Bedrichov, Mezni Louka, Trojanovice, Harrachov). However, Jetrichovice near Decin ("Bohemian Switzerland" in the northern part of the Czech Republic) has become the favorite venue among the regular MEM participants and last 12 years of the MEM were organized there (there has been only two exceptions since the year 2000).

Miroslav Fojta

fojta@ibp.cz

$\triangle$ Tomáš Navrátil

Navratil@jh-inst.cas.cz;

Tomas.Navratil@jh-inst.cas.cz

1 Institute of Biophysics of the AS CR, v.v.i., Královopolská 135, 61265 Brno, Czech Republic

2 J. Heyrovský Institute of Physical Chemistry of the AS CR, v.v.i., Dolejškova 3, 18223 Prague 8, Czech Republic
By its subtitle, the 47th HD was devoted to Electrochemistry of Organic and Bioactive Compounds. It comprised 25 lectures fitting into the general topics, including contributions oriented towards studies of mechanisms of electrochemical processes involving reducible or oxidizable organic species, development of novel materials for construction of electrochemical (bio)sensors, as well as analytical techniques designed for the determination of biologically active compounds (such as toxic substances, drugs or components of biopolymers) in various matrices. Attention was paid to electrochemistry of nucleic acids and proteins and its applications in biosensing. Interdisciplinary milieu of the meeting was strengthened by incorporation of contributions on organic synthesis of redox-labeled nucleic acids and on general aspects of protein-DNA interactions; both topics are closely related to applications of modern electrochemical techniques in biological research and in medical diagnostics. At the MEM conferences, similar topics were presented regularly and formed a significant part of the MEM XXXIV as well.

This issue contains a review on biophysical and electrochemical techniques used for protein-DNA interaction studies (related to 2 lectures presented at the 47th HD), a review on electroanalysis of antioxidants in pharmaceutical dosage forms (related to the lecture presented at the 47 th HD) and 13 original papers from 6 lectures at the 47th HD and another 7 lectures presented at the MEM XXXIV. These articles comprise a representative selection of contributions covering the above topics of both conferences.

Enjoy reading! 